\title{
THE ROLE OF ISLAMIC EDUCATION IN OVERCOMING YOUTH DISTINCTIONS AT RW 023 KELURAHAN JATI MAKMUR - KECAMATAN PONDOK GEDE KOTA BEKASI
}

\author{
PERAN PENDIDIKAN ISLAM DALAM MENANGGULANGI KENAKALAN \\ REMAJA \\ DI RW O23 KELURAHAN JATI MAKMUR - KECAMATAN PONDOK GEDE \\ KOTA BEKASI
}

\author{
Ristianti Azharita ${ }^{1}$ \\ ${ }^{1}$ Universitas Muhammadiyah Prof. DR. HAMKA \\ email: ristiantiazharita83@gmail.com
}

\section{Received: 19/04/2020, Accepted: 25/08/2020, Published: 29/08/2020}

\begin{abstract}
One of the problems often happen in society, such as teenager problem or deliquency, education and social interaction. Now, teenager life is often appeared by the complex problem that need to get attention from all elements. The adolescence is the transitional periode which is past all people from childhood to adult. The condition of teenages has been on transitional periode from childhood to adult periode. They can get consequence, namely can be effected by social media or invironment easily. Because of that, we have to anticipate for minimizing or preventing about teenager problem. Based on it, teenager has to been educated with Islamic education, in order that they can point out kind-personality as teenager and able to avoid immoral action that can damage theirselves and others. And they can show good attitude basen on Islamic education. The purpose of this research is knowing, that is there significant effect between Islamic education on resolve deliquency on $R W 023$ Kelurahan Jati Makmur Kecamatan Pondok Gede Bekasi. Responden in this research amounted to 46 people.
\end{abstract}

Keywords: education, Islamic and deliquency.

\begin{abstract}
ABSTRAK
Suatu permasalahan yang sering muncul di masyarakat adalah berkisar pada permasalahan remaja, pendidikan dan pergaulan di masyarakat. Kehidupan remaja sekarang ini sering dihadapkan pada permasalahan yang kompleks yang tentu sangat perlu mendapat perhatian semua pihak. Usia remaja merupakan masa peralihan yang ditempuh oleh seseorang, dari usia kanak-kanak menuju usia dewasa. Keadaan remaja yang masih dalam masa peralihan dari masa kanak-kanak menuju masa dewasa mengakibatkan mereka mudah terpengaruh baik dari berbagai media maupun lingkungan sekitarnya. Oleh karena itu dibutuhkan antisipasi untuk mengurangi atau mencegah munculnya kenakalan remaja. Berdasarkan hal di atas, maka para remaja perlu dididik dan dibekali dengan pendidikan Islam agar dapat menampilkan pribadi yang utuh sebagai seorang remaja yang baik dan terhindar dari tindakan-tindakan amoral yang dapat merugikan diri sendiri serta masyarakat dan berperilaku sesuai dengan ajaran Islam. Penelitian ini bertujuan untuk mengetahui apakah terdapat pengaruh yang signifikan antara pendidikan Islam dalam mengatasi kenakalan remaja di RW 023 Kelurahan Jati Makmur Kecamatan Pondok Gede Bekasi. Responden dalam penelitian ini berjumlah 46 orang.
\end{abstract}

Keyword: pendidikan, Islam dan kenakalan remaja. 


\section{A. PENDAHULUAN}

Pendidikan Islam merupakan proses pembentukan individu berdasarkan ajaran Islam yang diwahyukan Allah S.W.T kepada Nabi Muhammad S.A.W. Pendidikan Islam memberikan arti yang sangat penting sebagai sarana pembentukan tingkah laku di kalangan pelajar, perubahan kemampuan pelajar untuk bertingkah laku secara baru sebagai akibat dari hasil interaksi stimulus dan respons lingkungan yang didapatnya (Saihu, 2019: 165). Hal ini, karena pelajar merupakan generasi penerus bangsa dan agama. Di masa sekarang ini, ilmu dan teknologi terus berkembang sejalan dengan perkembangan manusia. Pola kehidupan pun semakin bergeser pada pola yang semakin universal. Suatu permasalahan yang sering muncul di masyarakat adalah berkisar pada permasalahan remaja, pendidikan dan pergaulan masyarakat. Kehidupan remaja sekarang ini sering dihadapkan pada permasalahan yang kompleks yang tentu sangat perlu mendapat perhatian semua pihak. Usia remaja merupakan masa peralihan yang ditempuh oleh seseorang, dari usia kanakkanak menuju usia dewasa. Keadaan remaja yang masih dalam masa peralihan dari masa kanak-kanak menuju masa dewasa mengakibatkan mereka mudah terpengaruh baik dari berbagai media maupun lingkungan sekitarnya. Oleh karena itu dibutuhkan antisipasi untuk mengurangi atau mencegah munculnya kenakalan remaja. Berdasarkan hal di atas, maka para remaja perlu dididik dan dibekali dengan pendidikan Islam agar dapat menampilkan pribadi yang utuh sebagai seorang remaja yang baik dan terhindar dari tindakan-tindakan amoral yang dapat merugikan diri sendiri serta masyarakat dan berperilaku sesuai dengan ajaran Islam. Mengingat pentingnya pendidikan Islam bagi remaja, maka peneliti tertarik untuk mengkaji pendidikan Islam di RW 023 Jati Makmur, dalam peranannya menanggulangi kenakalan remaja. Peneliti tertarik melakukan penelitian lebih lanjut dan menuangkannya dengan judul: "Peran Pendidikan Islam dalam Menanggulangi Kenakalan Remaja di Rw 023 Jati Makmur-Pondok Gede Bekasi"

\section{B. TINJAUAN PUSTAKA}

\section{Pengertian Pendidikan Islam}

Pendidikan adalah proses pengubahan sikap dan tata laku seseorang atau kelompok orang di dalam usaha mendewasakan manusia melalui upaya pengajaran dan pelatihan (Kemendikbud, 2016). Kata "pendidikan” yang umumnya 
kita gunakan sekarang, dalam bahasa arabnya adalah "tarbiyah", dengan kata kerja "rabba". Menurut Drajat, kata "pengajaran" dalam bahasa arabnya adalah "ta'lim" dengan kata kerjanyanya "alama". Pendidikan dan pengajaran dalam bahasa arabnya "tarbiyah wa ta'lim" sedangkan "pendidikan Islam" dalam bahasa arabnya adalah "tarbiyah Islamiyah" (2000: 25). Menurut Najib dan Mudzakkir, Tarbiyah dapat diartikan dengan proses transformai ilmu pengetahuan dari pendidik kepada peserta didik, agar ia memiliki sikap dan semangat yang tinggi dalam memahami dan menyadari kehidupannya, sehingga terbentuk ketakwaan, budi pekerti dan kepribadian yang luhur. Sebagai proses, tarbiyah menuntut adanya penjenjangan dalam transformasi ilmu pengetahuan, mulai dari pengetahuan yang dasar menuju pada pengetahuan yang sulit/tinggi (2010: 13). Allah S.W.T., berfirman dalam AlQur'an: kиипии rabbaanyyina bimaa kuntum tu'allimuunal-kitaaba wa bimaa kuntum tadrusuun

“...karena kamu mengajarkan Kitab dan karena kamu mempelajarinya!"

Pendidikan merupakan hal krusial pada kehidupan manusia dan sebuah usaha untuk menjadikan anak keturunan dapat mewarisi ilmu pengetahuan (Islam) (Saihu, 2020: 128). Bagi umat Islam agama adalah dasar (pondasi) utama dari keharusan berlangsungnya pendidikan karena ajaranajaran Islam yang bersifat universal mengandung aturan-aturan yang mengatur seluruh aspek kehidupan manusia baik yang bersifat ubudiyyah maupun yang bersifat muamalah.

Secara lebih rinci, Yusuf Al-Qardhawi dalam Azyumardi Azra (2012: 6) memberikan pengertian, pendidikan Islam adalah pendidikan manusia seutuhnya, akal dan hatinya, rohani dan jasmaninya, akhlak dan keterampilannya. Karena itu pendidikan Islam menyiapkan manusia untuk hidup baik dalam keadaan damai maupun perang dan menyiapkannya untuk menghadapi masyarakat dengan segala kebaikan dan kejahatannya, manis dan pahitnya.

Shaleh, A.R. dalam Yusriyah mengungkapkan bahwa pendidikan agama merupakan hal yang penting untuk mencapai hasil yang diharapkan dari pendidikan agama terutama pada jenjang sekolah di masa remaja yakni, siswa dapat menumbuh kembangkan keimanan dalam dirinya dan mampu mengembangkan akhlak budi pekerti yang baik serta mengenal nilai moral agama dalam hubungan manusia dengan alam dan manusia dengan Tuhannya. Selain itu siswa dapat meningkatkan bekal 
pengetahuan, penghayatan dan pengalaman agama dalam kehidupannya serta mampu mencari hubungan agama dengan ilmu pengetahuan dan mengaplikasikan pendidikan agama pada kehidupan pada kehidupan bermasyarakat. Pada umumnya masa ini adalah masa yang paling goncang, sehingga banyak faktor yang mempengaruhi siswa jauh dari agama $(2017,60)$.

Tidak dapat diragukan bahwa salah satu misi Rasulullah S.A.W. adalah menyempurnakan akhlak manusia, seperti yang dikatakan oleh beliau pada hadits yang berbunyi: “innamaa bu'itstu li'utammima makaarimal akhlaaq" yang artinya "Sungguh aku diutus menjadi Rasu tidak lain adalah untuk menyempurnakan akhlak yang mulia” (H.R. Ahmad).

Nabi Muhammad S.A.W. diutus mengembangkan kualitas kehidupan manusia, menyucikan moral mereka dan membekali mereka dengan bekal-bekal yang diperlukan untuk menjalani kehidupan di dunia dan di akhirat kelak. Firman Allah S.W.T: "Dan Kami tidak mengutus kamu, melainkan kepada umat manusia seluruhnya, sebagai pembawa berita gembira dan sebagai pemberi peringatan.” (Q.S. Saba': 28). Juga dalam ayat berikut: "Dan tiadalah Kami mengutusmu (Muhammad), melainkan untuk (menjadi) rahmat bagi semesta alam" (Q.S. Al-Anbiya': 107).

Sebagai pendidik dan sekaligus Rasul, misi kependidikan pertama Muhammad S.A.W. adalah menanamkan akidah yang benar, yakni akidah tauhid (mengesakan Allah S.W.T.), yang by extension, memahami seluruh fenomena alam dan kemanusiaan sebaga suatu kesatuan yang holistik. Dalam kerangka tauhid, dalam pengertian terakhir ini kemanusiaan dan dengan demkian sumber daya manusia adalah manusia yang memiliki kualitas seimbang: beriman, berilmu (iptek) dan beramal; cakap baik lahiriah maupun batiniah; berkualitas secara emosional dan rasional, atau memiliki EQ dan IQ yang tinggi. Krisis dalam kualitas SDM terjadi ketika harmoni semacam ini tidak lagi dipertimbangkan dan dipedulikan, seperti sering terjadi dalam pendidikan modern (Azra: 2012, 62).

Secara ideal pendidikan Islam memiliki peran yang penting dalam membentuk kualitas SDM, baik dalam hal ilmu pengetahuan dan teknologi maupun dalam pembentukan karakter. Untuk mewujudkan fungsi idealnya dalam hal peningkatan kualitas sumber daya manusia tersebut, pendidikan Islam haruslah seantiasa mengorientasikan diri untuk menjawab kebutuhan dan tantangan dalam 
masyarakat sebagai konsekuensi logis dari perubahan.

\section{Kenakalan Remaja}

Kids zaman now merupakan suatu kata yang menjadi trending dan viral. Istilah kids zaman now merupakan sindiran tentang perilaku nyeleneh para remaja yang melakukan hal-hal tidak baik. Penggunaan istilah kids zaman now menggambarkan keadaan anak-anak zaman sekarang. Jika dikaitkan kebiasaan anakanak zaman sekarang dengan yang sebelumnya, kita akan menemukan hal yang berbeda di situ. Misalnya, gaya hidup yang bergantung pada gadget (Renny Nirwana Sari: 2019, 171).

Remaja adalah masa peralihan dari kanak-kanak menuju dewasa. Seorang remaja sudah tidak lagi dapat dikatakan sebagai anak-anak, namun ia masih belum cukup matang untuk dapat dikatakan dewasa. Fase perkembangan masa remaja merupakan pusat perhatian. Oleh karena itu, pada masa remaja ini sering terjadi kegoncangan pada individu remaja , terutama di dalam nilai-nilai yang lama dan dalam memperoleh nilai-nilai yang baru untuk mencapai kedewasaan.

Menurut Sutjiningsih dalam Nusriyah (2017: 56), masa remaja merupakan masa peralihan antara masa kanak-kanak dan masa dewasa yang dimulai pada saat terjadinya kematangan seksual yaitu antara usia 11 atau 12 tahun sampai dengan usia 20 taun yaitu menjelang masa dewasa muda. Remaja dalam bahasa inggris adolescence dan bahasa latin adolescere yang berarti tumbuh atau tumbuh menjadi dewasa. Sedangkan dalam KBBI kata remaja memiliki tiga arti, yakni mulai dewasa, sudah sampai umur untuk kawin dan masa muda (Syamsu Yusuf, 2004: 184).

Seorang tokoh pendidikan pendidikan dan perkembangan, Jean Pieget menyatakan pandangannya tentang masa remaja, menurutnya masa remaja adalah usia dimana individu berintegrasi dengan masyarakat dewasa, usia dimana anak-anak lagi merasa di bawah tingkat orang-orang yang lebih tua melainkan berada dalam tingkatan yang sama sekurang-kurangnya dalam masalah hak. Masa remaja mempunyai retangan waktu sekitar usia 12-17 masa remaja lanjutan dari masa pubertas antara usia 9-13 tahun (Usman \& Inayahwati, 2011).

Menurut Muawanah (2012) dalam Renny Nirwana Sari (2019, 171), remaja mampu mengalami perubahan psikologi yang tidak terkontrol yang memiliki kecenderungan remaja akan terlibat kenakalan yang lebih beresiko. Menurut Setiano (2013) dalam Renny NS (2019, 
171-172), remaja yang rentan akan resiko kenakalan remaja terdapat pada siswa sekolah menengah pertama yang termasuk remaja awal pada usia 12 sampai 15 tahun dimana pada tahap remaja awal inilah merupakan usia rentan pengaruh positif dan pengaruh negatif, baik dari luar diri remaja, maupun dari dalam diri remaja. Dampak positifnya mereka akan tumbuh dan berkembang mencari jati dirinya, pencapaian kemandirian dan identitas sangat menonjol, pemikiran semakin logis, abstrak dan idealis.

Remaja memiliki kecenderungan ingin bergaul atau berkumpul dengan teman sebayanya dibandingkan lingkungan keluarganya, karena mereka lebih nyaman dengan teman sebayanya untuk menceritakan semua yang dialaminya ketimbang menceritakan kepada keluarganya, akibatnya mereka bergaul terlalu bebas dan hingga melampaui batas (Hurlock, 1992). Mereka bisa menjadi anak jalanan, terlibat dengan pergaulan bebas, bahkan melakukan tindakan kriminal. Hal tersebut dapat mengubah pola pikir dan kecenderungan remaja untuk tidak semangat belajar, melakukan pelanggaran norma-norma sosial hingga norma-norma agama, remaja yang labil secara emosi dan masih senang akan halhal baru serta keingin-tahuan yang besar dengan istilah "coba-coba" hingga akhirnya mereka terjebak dengan seks bebas, narkoba, minum-minuman keras. Selain masalah penyimpangan tersebut, masa remaja zaman now juga berimbas pada pemakaian smartphone yang amat digandrungi para remaja. Namun sangat disayangkan penggunaan smartphone oleh remaja justru dimanfaatkan untuk mengakses suguhan-suguhan yang semestinya bukan untuk usia mereka, seperti konten pornografi yang sangat mudah diakses.

Menurut Sumara dkk, ulah para remaja yang masih dalam taraf pencarian jati diri sering sekali mengusik ketenangan orang lain. Kenakalan-kenakalan ringan yang mengganggu ketentraman lingkungan sekitar seperti sering keluar malam dan menghabiskan waktunya hanya untuk hura-hura seperti minum-minuman keras, menggunakan obat-obatan terlarang, berkelahi, berjudi dan lain-lainnya itu akan merugikan dirinya sendiri, keluarga dan orang lain ang ada di sekitarnya (2017, 347)

Pada kompasiana.com (Setyawan, 2018) menuliskan bahwa Komisioner Komisi Perlindungan Anak Indonesia (KPAI), yaitu Siti Hikmawaty mengatakan, "pihaknya telah melihat data hasil screening anak sekolah dasar yang 
dilakukan Kementran Kesehatan (Kemenkes) pada akhir 2017 dan dipublikaskan pada Maret 2018. Data itu memperlihatkan screening keterpaparan adiksi pornografi kepada anak sekolah dasar yang dilakukan di 4 (empat) provinsi, yakni Aceh, Jawa Tengah, DKI dan DIY. Hasil riset yang dilakukan KPAI yaitu dari 6000 sampling yang diambil datanya ternyata $91,85 \%$ anak telah terpapar pornografi; $6,30 \%$ sudah mengalami adiksi pornografi ringan dan $0,07 \%$ mengalami adiksi berat," ujar Siti kepada Okezone, (Sabtu 31/3/2018).

Menurut KPAI dalam Renny NS (2019, 172)Adanya fakta yang mengkhawatirkan berdasarkan hasil survei KPAI terhadap 4500 remaja mengungkap, 97\% remaja pernah menonton atau mengakses pornografi dan 93\% pernah berciuman bibir. Survei yang dilakukan di 12 kota besar tahun 2017, juga menunjukkan $62,7 \%$ responden pernah berhubungan badan dan $21 \%$ diantaranya telah melakukan aborsi. Hasil survei tersebut dikuatkan dikuatkan dg fakta, pulhan siswa SMP di Bandung, Jawa Barat telah berprofesi menjadi pekerja seks komersial (PSK). Ada yang lebih mengkhawatirkan, yaitu data yang berhasil diperoleh pada program Save the Children yang dilakukan pada tahun 2017 di kota besar yaitu Jawa Barat menunjukkan di antara para PSK remaja tersebut cukup dibayar dengan pulsa telepon seluler. Datadata tersebut memberi gambaran kepada kita, bahwa sudah sejak lama pornografi akrab dengan dunia remaja.

Ada banyak faktor yang menyebabkan kenakalan ini terjadi, setidaknya ada tiga faktor yang mempengaruhi perilaku seorang anak remaja, yaitu:

a. Faktor lingkungan. Lingkungan adalah faktor yang paling mempengaruhi perilaku dan watak anak, jika dia hidup dan berkembang di lingkungan yang buruk maka akhlaknya pun akan seperti itu adanya, sebaliknya jika dia berada di lingkungan yang baik maka ia akan menjadi baik pula. Rasulullah bersabda: "Dari Abu Hurairah dari nabi bersabda: seseorang itu atas din saudaranya. Maka lihatlah salah seorang di antara kalian, siapa yang ditemani." (H.R. Bukhari).

b. Pendidikan dan pembinaan dari orang tua. Orang tua adalah orang yang paling bertanggungjawab dengan akhlak dan perilaku anaknya. Pembinaan dari orang tua adalah faktor terpenting dalam memperbaiki dan membentuk 
generasi yang baik. Rasulullah bersabda: "Setiap anak itu dilahirkan dalam keadaan fitrah. Maka bapaknyalah yang menjadikan ia yahudi, nasrani atau majusi." (H.R. Bukhari).

c. Pemerintahan dalam hal ini yang lebih spesifiknya adalah lembaga pendidikan atau sekolah. Sekolah yang kita lihat hari ini jarang yang mendidik untuk menjadi orang yang bertakwa. Mereka hanya mengajarkan ilmu-ilmu dunia dan tidak mengajarkan ilmu agama. Maka sangat penting bagi para orang tua untuk memilihkan lingkungan sekolah yang baik untuk anak-anaknya. Seorang tabi'in terkenal Muhammad bin Sirin berkata: "Sesungguhnya ilmu ini (ilmu sanad) adalah agama maka lihatlah dari siapa kamu mengambil agama kamu." (muqaddimah shahih muslim).

\section{Pendidikan Islam dalam Menangani}

\section{Kenakalan Remaja}

Menurut M. Athiyah al-Abrasyi dalam M. Ainul Yaqin (2016, 309), dalam pendidikan Islam, tujuan pokok dan terutama adalah mendidik budi pekerti dan pendidikan jiwa. Tujuan dari pendidikan Islam adalah taqarrub kepada Allah dan kesempurnaan manusia untuk mencapai kebahagiaan dunia dan akhirat.

Kondisi yang haronis dan sinergis merupakan satu kesatuan yang terintegrasi. Apa yang diyakini baik di rumah, baik pula di sekolah dan masyarakat. Pendidikan mempunyai peranan penting dalam pembinaan dan pengembangan anak, terutama berkenaan dengan penanaman nilai-nilai keagamaan sejak dini.

Sebelum anak memasuki pendidikan di lembaga sekolah, terlebih dahulu anak akan menerima pendidikan di lingkungan keluarganya. Menyikapi hal itu pendidikan di keluarga perlu diterapkan kepada anak mulai sejak dini, karena apapun yang dilakukan oleh orang tuanya akan mudah untuk ditiru dan terekam dalam ingatan anak. Maka di dalam keluarga, terdapat peran orang tua yang sangat berpengaruh dalam dalam menanamkan nilai-nilai keagamaan, karena orang tua merupakan madrasah pertama bagi anak-anaknya.

Rasulullah mengatakan dalam haditsnya:

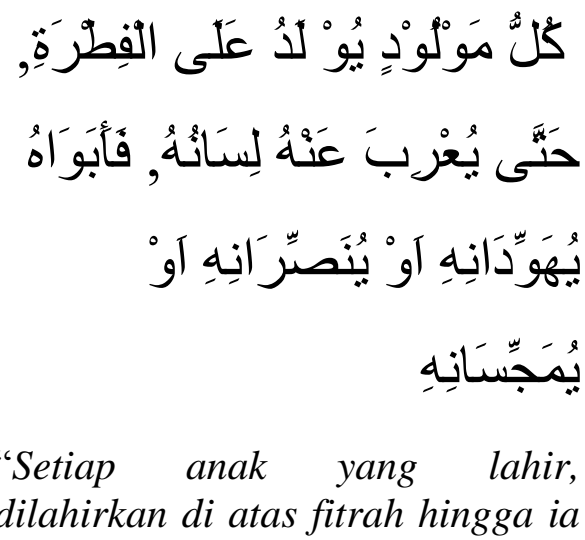


fasih (berbicara). Kedua orang tuanyalah yang menjadikannya Yahudi, Nasrani, atau Majusi."

\section{(H.R. Baihaqi dan Ath-} Thabrani)

Menurut Sutikno (2013: 292), pengenalan terhadap agama sejak dini diperlukan oleh anak didik agar mempunyai kepribadian sesuai dengan unsur moralitas yang ada di dalam agama. Seorang yang tidak pernah mendapatkan pendidikan agama pada waktu kecilnya, maka pada masa dewasanya nanti tidak akan merasakan pentingnya agama dalam kehidupannya atau bahkan mungkin kurang perduli terhadap agama.

Selama ini penerapan pendidikan Islam kurang menyentuh substansi dari pendidikan Islam itu sendiri sehingga sering mengalami kesulitan dalam pengamalannya. Dengan demikian, perlu dilakukan beberapa upaya dalam menanggulangi kenakalan remaja yaitu dengan cara preventif, represif dan kuratif. Preventif yaitu suatu usaha untuk menghindari kenakalan, jauh sebelum kenakalan itu terjadi dan terlaksana atau agar kenakalan itu tidak terjadi. Represif adalah usaha atau tindakan untuk menindak dan menahan kenakalan remaja sedini mungkin atau menghalangi peristiwa yang lebih hebat. Cara kuratif adalah usaha untuk menyembuhkan atau memperbaiki apabila kenakalan siswa itu sudah terjadi.

\section{METODE PENELITIAN}

Penelitian ini merupakan penelitian non eksperimen dengan pendekatan kuantitatif untuk melihat adanya hubungan pengetahuan pendidikan Islam dan pengaruhnya terhadap tingkat kenakalan remaja. Populasi yang digunakan yaitu seluruh remaja yang bertempat tinggal di RW 023 Jati Makmur-Pondok Gede Bekasi. Sampel yang digunakan berjumlah 47 responden dengan teknik simple random yang merupakan pengambilan sampel secara acak.

Alat pengumpulan data dalam penelitian ini adalah kuesioner. kuesioner ini meliputi biodata, informasi umum tentang pendidikan Islam dan kenakalan remaja. Analisis data dilakukan secara kuantitatif dan disesuaikan dengan tujuan yang akan dicapai pada penelitian.

Adapun sistem pemberian skor dari data angket mengenai Pendidikan Islam sebagai berikut:

1. Apabila jawaban tidak pernah maka diberi skor 1

2. Apabila jawaban pernah maka diberi skor 2

3. Apabila jawaban sering maka diberi skor 3 
4. Apabila jawaban selalu maka diberi skor 4

Adapun sistem pemberian skor dari data angket mengenai kenakalan remaja sebagai berikut:

1. Apabila jawaban tidak pernah maka diberi skor 4

2. Apabila jawaban pernah maka diberi skor 3

3. Apabila jawaban sering maka diberi skor 2

4. Apabila jawaban selalu maka diberi skor 1

Dalam penelitian ini, penulis menggunakan metode deskriptif analisis, yaitu "penelitian yang menggambarkan apa adanya tentang suatu variabel, gejala atau keadaan yang sebenarnya dari fenomena objek yang diteliti" (Suharsimi Arikunto: 2005). Penelitian ini bermaksud mengetahui sejauh mana suatu variabel berhubungan dengan variabel lain. Selanjutnya akan terlihat seberapa besar peran Pendidikan Islam dalam menanggulangi kenakalan remaja di RW 023 Jati Makmur-Pondok Gede Bekasi.

Untuk mendapatkan kesimpulan dari penelitian ini dengan melakukan pengolahan dan analisis data. Kemudian untuk mengetahui Peran Pendidikan Islam (variabel $\mathrm{X}$ ) dalam Menanggulangi Kenakalan Remaja (variabel Y) peneliti menggunakan rumus product moment dari Carl Pearson sebagai teknik analisanya. Cara operasionalnya data dilakukan melalui tahap sebagai berikut: (Anas Sudjono: 2001)

1. Mencari angka korelasi dengan rumus:

$$
\mathrm{r}_{\mathrm{xy}}=\frac{\mathrm{N} \Sigma \mathrm{XY}-(\Sigma \mathrm{X})(\Sigma \mathrm{Y})}{\sqrt{ }\left\{\mathrm{N} \Sigma \mathrm{X}^{2}-(\Sigma \mathrm{X})^{2}\right\}\left\{\mathrm{N} \Sigma \mathrm{Y}^{2}-(\Sigma \mathrm{Y})^{2}\right\}}
$$

Keterangan:

Rxy = Angka indeks korelasi " $\mathrm{r}$ " product moment

$\Sigma \mathrm{X} \quad=$ Jumlah skor dalam sebaran $\mathrm{X}$

$\Sigma \mathrm{Y} \quad=$ Jumlah skor dalam sebaran $\mathrm{Y}$

$\Sigma \mathrm{XY}=$ Jumlah hasil kali skor $\mathrm{X}$ dengan skor Y

$\Sigma \mathrm{X}^{2} \quad=$ Jumlah skor yang dikuadratkan dalam sebaran X

$\Sigma \mathrm{Y}^{2} \quad=$ Jumlah skor yang dikuadratkan dalam sebaran $\mathrm{Y}$

$\mathrm{N}=$ = Banyaknya subyek (Number of Case)

2. Memberikan interpretasi terhadap rxy

a. Memberikan interpretasi sederhana dengan cara memcocokkan hasil perhitungan indeks korelasi " $r$ " product miment seperti di bawah ini: 
Tabel 1

Indeks Korelasi Product

Moment

\begin{tabular}{|c|c|}
\hline $\begin{array}{c}\text { Besarnya } \\
\text { “r" } \\
\text { Product } \\
\text { Moment } \\
\text { (rxy) }\end{array}$ & Imterpretasi \\
\hline $0,00-0,20$ & $\begin{array}{l}\text { Antara variabel } \mathrm{X} \text { dan } \\
\text { variabel } \mathrm{Y} \text { memang } \\
\text { terdapat korelasi, akan } \\
\text { tetapi korelasi itu sangat } \\
\text { lemah atau sangat rendah } \\
\text { sehingga korelasi itu } \\
\text { diabaikan (dianggap tidak } \\
\text { ada korelasi antar variabel } \\
\mathrm{X} \text { dan variabel } \mathrm{Y} \text { ). }\end{array}$ \\
\hline $0,20-0,40$ & $\begin{array}{l}\text { Antara variabel } \mathrm{X} \text { dan } \\
\text { variabel } \mathrm{Y} \text { terdapat korelasi } \\
\text { yang lemah atau rendah. }\end{array}$ \\
\hline $0,40-0,70$ & $\begin{array}{l}\text { Antara variabel } \mathrm{X} \text { dan } \\
\text { variabel Y terdapat korelasi } \\
\text { yang sedang atau cukupan. }\end{array}$ \\
\hline $0,70-0,90$ & $\begin{array}{l}\text { Antara variabel } \mathrm{X} \text { dan } \\
\text { variabel } \mathrm{Y} \text { terdapat korelasi } \\
\text { yang kuat atau tinggi. }\end{array}$ \\
\hline $0,90-1,00$ & $\begin{array}{l}\text { Antara variabel X dan } \\
\text { variabel Y terdapat korelasi } \\
\text { yang sangat kuat atau } \\
\text { sangat tinggi }\end{array}$ \\
\hline
\end{tabular}

b. Interpretasi terhadap indeks korelasi product moment dengan jalan berkonsultasi pada tabel nilai "r" product moment. Apabila cara ini akan ditempuh maka prosedur yang akan dilalui adalah sebagai berikut:

1) Merumuskan Hipotesis Alternatif (Ha) dan Hipotesis Nol (Ho)

2) Menguji kebenaran dari hipotesa yang telah dirumuskan dengan jalan membandingkan besarnya "r" product moment dengan " $r$ " yang tercantum dalam tabel (r) pada taraf signifikansi $5 \%$ namun terlebih dahulu mencari derajat bebasnya (db) atau Degrees of Freedom-nya (df) dengan rumus sebagai berikut:

$\mathrm{Df}=\mathrm{N}-\mathrm{nr}$

Df $=$ Degrees of Freedom (derajat bebas)

$\mathrm{N}=$ Jumlah subyek penelitian (sampel)

$\mathrm{Nr}=$ Jumlah variabel

Kemudian untuk mengetahui berapa besar kontribusi variabel $\mathrm{X}$ menunjang keberhasilan variabel Y, maka dihitung terlebih dahulusuatu 
koefisien yang disebut coefficient

determination (koefisien penentuan) dengan rumus sebagai berikut:

$\mathrm{KD}=r^{2} \times 100 \%$

Keterangan:

$\mathrm{KD}=$ Coefficient of Determination (Kontribusi variabel $\mathrm{X}$ terhadap

Variabel $\mathrm{Y}$
$\mathrm{R}=$ Koefisien korelasi
antara variabel $\mathrm{X}$ dan
variabel $\mathrm{Y}$

\section{PEMBAHASAN}

\section{Deskripsi dan Analisis Data}

Sebagaimana telah dijelaskan bahwasannya tujuan diadakannya penelitian ini adalah untuk mengetahui kenakalan apa saja yang dilakukan oleh remaja, serta sejauhmana peran pendidikan Islam dalam menanggulangi kenakalan remaja di RW 023 Kelurahan Jati Makmur Kecamatan Pondok Gede Kota Bekasi Jawa Barat. Peulis berusaha untuk mengukur besarnya korelasi antara variabel $\mathrm{X}$ yaitu Pendidikan Islam dan variabel Y yaitu Kenakalan Remaja di RW 023 Kelurahan Jati Makmur Kecamatan Pondok Gede Kota Bekasi Jawa Barat.
Angket disebar kepada remaja di RW 023 Kelurahan Jati Makmur Kecamatan Pondok Gede Kota Bekasi Jawa Barat. Setelah diperoleh data dari hasil angket, data yang terkumpul dianalisis secara kuantitatif melalui tabel distribusi frekuensi dengan persentase, kemudian memberi skor pada setiap data untuk kemudian dihitung dan dianalisis. Dalam proses analisis, penulis melakukan perhitungan dengan menggunakan teknik analisis korelasional, yaitu teknik analisis statistik mengenai hubungan antara dua variabel.

Setelah memperoleh angka persentase dari masing-masing angket, maka langkah berikutnya adalah mencari angka korelasi antara variabel $\mathrm{X}$ dan variabel $\mathrm{Y}$ dengan menggunakan rumus korelasi product moment sebagai berikut:

$$
\frac{r_{x y}=}{\sqrt{ } N \Sigma X Y-(\Sigma X)(\Sigma Y)}
$$

Namun sebelumnya akan disajikan data tentang pendidikan Islam (variabel X) dan data tentang kenakalan remaja di RW 023 Kelurahan Jati Makmur Kecamatan Pondok Gede Kota Bekasi Jawa Barat (variabel Y) berdasarkan scoring: Tahapan selanjutnya adalah memperkalikan skor variabel $\mathrm{X}$ dengan skor variabel $\mathrm{Y}$ (yaitu: $\mathrm{XY}$ ), setelah selesai lalu dijumlahkan 
untuk mendapat hasil $\Sigma X Y$. Kemudian mengkuadratkan skor variabel $\mathrm{X}$ yang selanjutnya dijumlahkan untuk mengetahui hasil $\Sigma X^{2}$ dan mengkuadratkan skor variabel $\mathrm{Y}$ yang selanjutnya dijumlahkan untuk mengetahui hasil $\Sigma \mathrm{Y}^{2}$.

Tabel 2

Hasil Korelasi

\begin{tabular}{|c|c|c|c|c|c|}
\hline $\begin{array}{c}\text { No } \\
\text { Respo } \\
\text { neden }\end{array}$ & $\mathbf{X}$ & $\mathbf{Y}$ & $\mathbf{X}^{2}$ & $\mathbf{Y}^{\mathbf{2}}$ & $\mathbf{X Y}$ \\
\hline 1 & 33 & 36 & 1089 & 1296 & 1188 \\
\hline 2 & 33 & 37 & 1089 & 1369 & 1221 \\
\hline 3 & 33 & 37 & 1089 & 1369 & 1221 \\
\hline 4 & 26 & 38 & 676 & 1444 & 988 \\
\hline 5 & 32 & 38 & 1024 & 1444 & 1216 \\
\hline 6 & 32 & 38 & 1024 & 1444 & 1216 \\
\hline 7 & 32 & 38 & 1024 & 1444 & 1216 \\
\hline 8 & 33 & 39 & 1089 & 1521 & 1287 \\
\hline 9 & 32 & 39 & 1024 & 1521 & 1248 \\
\hline 10 & 32 & 39 & 1024 & 1521 & 1248 \\
\hline 11 & 29 & 39 & 841 & 1521 & 1131 \\
\hline 12 & 33 & 39 & 1089 & 1521 & 1287 \\
\hline 13 & 30 & 39 & 900 & 1521 & 1170 \\
\hline 14 & 38 & 40 & 1444 & 1600 & 1520 \\
\hline 15 & 33 & 40 & 1089 & 1600 & 1320 \\
\hline 16 & 26 & 40 & 676 & 1600 & 1040 \\
\hline 17 & 29 & 40 & 841 & 1600 & 1160 \\
\hline 18 & 27 & 40 & 729 & 1600 & 1080 \\
\hline 19 & 32 & 40 & 1024 & 1600 & 1280 \\
\hline 20 & 35 & 40 & 1225 & 1600 & 1400 \\
\hline 21 & 34 & 40 & 1156 & 1600 & 1360 \\
\hline 22 & 34 & 39 & 1156 & 1521 & 1326 \\
\hline 23 & 36 & 39 & 1296 & 1521 & 1404 \\
\hline 24 & 33 & 39 & 1089 & 1521 & 1287 \\
\hline 25 & 29 & 39 & 841 & 1521 & 1131 \\
\hline 26 & 27 & 35 & 729 & 1225 & 945 \\
\hline 27 & 29 & 37 & 841 & 1369 & 1073 \\
\hline 28 & 33 & 39 & 1089 & 1521 & 1287 \\
\hline 29 & 36 & 39 & 1296 & 1521 & 1404 \\
\hline 30 & 32 & 38 & 1024 & 1444 & 1216 \\
\hline 31 & 28 & 37 & 784 & 1369 & 1036 \\
\hline 32 & 32 & 37 & 1024 & 1369 & 1184 \\
\hline 33 & 35 & 38 & 1225 & 1444 & 1330 \\
\hline
\end{tabular}

\begin{tabular}{|c|c|c|c|c|c|}
\hline 34 & 34 & 38 & 1156 & 1444 & 1292 \\
\hline 35 & 34 & 37 & 1156 & 1369 & 1258 \\
\hline 36 & 23 & 40 & 529 & 1600 & 920 \\
\hline 37 & 36 & 38 & 1296 & 1444 & 1368 \\
\hline 38 & 36 & 39 & 1296 & 1521 & 1404 \\
\hline 39 & 27 & 39 & 729 & 1521 & 1053 \\
\hline 40 & 29 & 37 & 841 & 1369 & 1073 \\
\hline 41 & 33 & 38 & 1089 & 1444 & 1254 \\
\hline 42 & 30 & 36 & 900 & 1296 & 1080 \\
\hline 43 & 31 & 37 & 961 & 1369 & 1147 \\
\hline 44 & 36 & 36 & 1296 & 1296 & 1296 \\
\hline 45 & 24 & 36 & 576 & 1296 & 864 \\
\hline 46 & 10 & 26 & 100 & 676 & 260 \\
\hline $\mathbf{N = 4 6}$ & $\mathbf{\Sigma}$ & $\mathbf{\Sigma}$ & $\mathbf{\Sigma} \mathbf{X}^{2}=$ & $\mathbf{\Sigma} \mathbf{Y}^{2}=\mathbf{6}$ & $\mathbf{\Sigma X Y =}$ \\
& $\mathbf{X}$ & $\mathbf{Y}$ & $\mathbf{4 5 4 8 5}$ & $\mathbf{6 7 2 7}^{\mathbf{5 4 6 8 9}}$ & $\mathbf{5 4}$ \\
& $\mathbf{1 4}$ & $\mathbf{1 7}$ & & & \\
& $\mathbf{1 4}$ & $\mathbf{4 9}$ & & & \\
\hline
\end{tabular}

Dari data yang diperoleh dapat diketahui:

$\mathrm{N} \quad=46$

$\Sigma X=1431$

$\Sigma \mathrm{Y} \quad=1749$

$\Sigma X^{2}=45485$

$\Sigma Y^{2}=66727$

$\Sigma X Y=54689$

Maka perhitungannya adalah sebagai berikut:

$\mathrm{r}_{\mathrm{xy}}=\frac{\mathrm{N} \Sigma \mathrm{XY}-(\Sigma \mathrm{X})(\Sigma \mathrm{Y})}{\sqrt{\left\{\mathrm{N} \Sigma \mathrm{X}^{2}-(\Sigma \mathrm{X})^{2}\right\}\left\{\mathrm{N} \Sigma \mathrm{Y}^{2}-(\Sigma \mathrm{Y})^{2}\right\}}}$
$\mathrm{r}_{\mathrm{xy}}=\frac{(46 \times 5468)-(1431)(1749)}{\sqrt{\left\{(46 \times 45485)-(1431)^{2}\right\}\{(46 \times 66727)-}}$ $\left.(1749)^{2}\right\}$

$\mathrm{r}_{\mathrm{xy}}=\sqrt{\sqrt{\{(2092310-2047761)(3069442-}}$ 3059001)\}

$$
\begin{aligned}
& r_{x y}=\frac{12875}{\sqrt{\{(44549)(10441)\}}} \\
& r_{x y}=\frac{12875}{\sqrt{465136109}} \\
& r_{x y}=\frac{12875}{21.567,014} \\
& r_{x y}=\mathbf{0 , 5 9 6}
\end{aligned}
$$


Setelah didapat angka indeks korelasi "r" Product Moment, yakni rxy = 0,596.

Kemudian dilakukan penarikan kesimpulan sebagai berikut:

1. Memberikan interpretasi secara kasar (sederhana)

Dari interpretasi secara kasar (sederhana) dapat diketahui bahwa terdapat korelasi antara variabel $\mathrm{X}$ dan variabel Y yakni korelasi sedang atau cukup $(0,40-0,70)$. Jadi semakin baik pemberian pendidikan Islam maka akan semakin menurun tingkat kenakalan remaja di RW 023 Jati Makmur Pondok Gede Bekasi.

2. Memberikan interpretasi terhadap angka indeks korelasi " $r$ " product moment, dengan jalan berkonsultasi pada tabel nilai ' $r$ ' product moment yang biasanya selalu tercantum dalam buku-buku statistik sebagai lampiran. Apabila cara yang kedua ini yang kita tempuh maka prosedur yang kita lalui secara berturut-turut adalah sebagai berikut:

a. Merumuskan (membuat) Hipotesis Alternatif (Ha) dan Hipotesis Nihil atau Hipotesis Nol (Ho). Adapun hipotesisnya sebagai berikut:

Ho: Tidak ada (tidak terdapat) peranan positif yang signifikan pendidikan Islam dalam mengatasi kenakalan remaja di RW 023 Jati Makmur Pondok Gede Bekasi.

Ha: ada (terdapat) peranan positif yang signifikan pendidikan Islam dalam menanggulangi kenakalan remaja di RW 023 Jati Makmur Pondok Gede Bekasi.

b. Menguji kebenaran atau kepalsuan dari hipotesis yang telah kita ajukan, dengan jalan membandingkan besarnya " $r$ " yang telah diperoleh dari proses perhitungan dengan besarnya " $r$ " yang tercantum dalam tabel nilai "r" Product Moment, dengan terlabih dahulu mencari derajat bebasnya (df) yang rumusnya sebagai berikut:

$\mathrm{df}=\mathrm{N}-\mathrm{nr}$

keterangan:

df : degrees of freedom

$\mathrm{N}$ : Number of case

$\mathrm{Nr}$ : banyaknya variabel yang

dikorelasikan

Dapat diketahui nilai $\mathrm{N}=$ 46, dan nilai $\mathrm{Nr}=2$, jadi derajat bebasnya adalah:

$\mathrm{df}=\mathrm{N}-\mathrm{nr}$

$\mathrm{df}=46-2$

$\mathrm{df}=44$ 
Memeriksa tabel " $\mathrm{r}$ " product moment dengan $\mathrm{df}=46$ pada taraf signifikan $5 \%$ diperoleh pada tabel yakni 0,284, sedangka pada df $=40$ pada taraf signifikansi $5 \%$ adalah $0,304 . \mathrm{df}=$ 44, berada antara $\mathrm{df}=46 \mathrm{dan} \mathrm{df}=$ 40. Jadi pada taraf signifikansi $5 \%$ $\operatorname{rxy}=\mathbf{0 , 5 9 6}>\mathbf{0 , 2 8 4}$.

Dengan demikian Ha diterima dan Ho ditolak. Terdapat hubungan yang signifikan antara variabel $\mathrm{X}$ dan variabel Y. Dapat diinterpretasikan bahwasannya terdapat korelasi negatif yang signifikan antara pendidikan Islam dalam menanggulangi kenakalan remaja di RW 023 Jati Makmur Pondok Gede Bekasi. Jadi semakin sering pendidikan Islam diberikan/diajarkan maka akan semakin menurun tingkat kenakalan remaja yang dilakukan oleh anak remaja RW 023 Jati Makmur Pondok Gede Bekasi.

Kemudian untuk mengetahui berapa besar kontribusi variabel $\mathrm{X}$ menunjang keberhasilan variabel $\mathrm{Y}$, maka dihitung terlebih dahulu suatu koefisien yang disebut coefficient of determination (koefisien penentuan). Koefisien determinasi merupakan langkah akhir dari analisis data penelitian ini. Perhitungan ini digunakan untuk mengetahui kontribusi pendidikan Islam (variabel $\mathrm{X}$ ) dalam menangani kenakalan remaja (variabel Y) dengan rumus sebagai berikut:

$$
\mathrm{KD}=\left(\mathrm{r}_{\mathrm{xy}}\right)^{2} \times 100 \%
$$

Keterangan:

KD : Koefisien Determination

(kontribusi variabel $\mathrm{X}$ terhadap variabel Y)

$\mathrm{R}$ : Koefisien korelasi antara variabel $\mathrm{X}$ dan variabel $\mathrm{Y}$

$$
\begin{aligned}
\mathrm{KD} & =r^{2} \times 100 \% \\
& =(0,596)^{2} \times 100 \% \\
& =0,3552 \\
& =\mathbf{3 5 , 5 2 \%}
\end{aligned}
$$

Dengan hasil tersebut di atas, maka dapat dikatakan bahwasannya pendidikan Islam yang diajarka kepada para remaja memberikan kontribusi sebesar 35,52\% dalam mengatasi kenakalan remaja di RW 023 Jati Makmur Pondok Gede Bekasi.

\section{Interpretasi Data}

Interpretasi data yang disajikan berkut ini, mengacu pada permasalahan yang telah dirumuskan pada BAB I. Masalah tersebut yaitu kenakalan apa saja yang dilakukan oleh remaja di RW 023 Kelurahan Jati Makmur Kecamatan Pondok Gede Kota Bekasi serta sejauh mana pengaruh pendidikan Islam dalam mengatasi kenakalan remaja. 
Berdasarkan hasil penelitian menunjukkan bahwa terdapat pengaruh yang signifikan antara pendidikan Islam dalam mengatasi kenakalan remaja di RW 023 Kelurahan Jati Makmur Kecamatan Pondok Gede Kota Bekasi.

Pada kajian teori penulis paparkan beberapa teori yang mengatakan bahwasannya pendidikan Islam akan memberikan pengaruh yang positif dalam mengatasi kenakalan remaja. Setelah diadakan penelitian adakah pengaruh pendidikan Islam dalam mengatasi kenakalan remaja di RW 023 Kelurahan Jati Makmur Kecamatan Pondok Gede Kota Bekasi, ternyata penulis simpulkan dari hasil penelitian bahwa pendidikan Islam cukup memberikan pengaruh positif dalam mengatasi kenakalan remaja di RW 023 Kelurahan Jati Makmur Kecamatan Pondok Gede Kota Bekasi.

\section{E. KESIMPULAN}

Adapum uraian dan analisis data yang telah dipaparkan pada bab-bab sebelumnya berdasarkan data yang terhimpun dari lokasi penelitian di RW 023 Kelurahan Jati Makmur Kecamatan Pondok Gede Kota Bekasi maka dapat disimpulkan bahwa remaja di wilayah tersebut memiliki tingkat kenakalan yang masih relatif rendah. Kenakalan yang sering dilakukan oleh remaja adalah menentang atau membantah orang tua, melanggar peraturan sekolah, merokok, berkelahi dengan teman dan sedikit yang melakukan kenakalan jenis membaca majalah porno dan menonton videonya.

Adanya pengaruh antara pendidikan Islam dalam mengatasi kenakalan remaja di RW 023 Kelurahan Jati Makmur Kecamatan Pondok Gede Kota Bekasi. Terbukti dari hasil pengujian hipotesis didapat rxy sebesar 0,596. Setelah jumlah tersebut dikonsultasikan pada interpretasi angka indeks korelasi "r" Product Moment, maka dapat ditarik kesimpulan bahwa antara pendidikan Islam (variabel X) dalam menanggulangi kenakalan remaja di RW 023 Kelurahan Jati Makmur Kecamatan Pondok Gede Kota Bekasi (variabel Y) terdapat korelasi yang sedang atau cukup.

\section{SARAN}

Berdasarkan pengamatan penulis terhadap hasil penelitian, ada beberapa saran yang dikemukakan oleh penulis:

1. Orang tua diharapkan selalu memberikan pendidikan Islam sehingga mereka memiliki nilai-nilai religius yang tinggi sehingga sehat mentalnya, yang pada akhirnya akan membentuk prilaku yang bermoral.

2. Orang tua hendaknya memberikan kasih dan perhatian yang cukup 
kepada anak-anaknya, agar terjalin hubungan emosional yang baik dengan anak-anaknya.

3. Orang tua hendaknya menciptakan lingkungan yang Islami di rumahnya, sehingga meminimalisir segala bentuk kenakalan remaja.

Peneliti mengucapkan terima kasih yang sedalam-dalamnya kepada UHAMKA dan ketua Lemlitbang atas dukungan yang diberikan dan berbagai pihak yang telah membantu terlaksanannya penelitian ini.

\section{DAFTAR PUSTAKA}

\section{Sumber dari Jurnal/Penelitian}

Arjoni. (2017). Pendidikan Islam dan Kenakalan Remaja. Turast: Jurnal Penelitian dan Pengabdian, 5(2): 189204.

Dadan Sumara, dkk. (2017). Kenakalan Remaja dan Penanganannya. Jurnal Penelitian dan PPM, 4(2).: 129-389.

Fitriyah, T. (2017). Potret Kenakalan Remaja dan Relevansinya dengan Pendidikan Indonesia. Journal of Islamic Education Policy, 2(2): 93103.

Ivong Rusdiyanti, dkk. (2019). FaktorFaktor yang Melatarbelakangi Kenakalan pada Remaja di Yayasan Wagas Limpua Banjarmasin. HealthyMu Journal, 3(1).: 14-24.

Mannuhung, S. (2019). Penanggulangan Tingkat Kenakalan Remaja dengan Bimbingan Agama Islam. TO MAEGA: Jurnal Pengabdian Masyarakat, 2(1).: 9-16.
Saihu dan Mailana, A. (2019). Teori Pendidikan

Behavioristik

Pembentukan Karakter Masyarakat Muslim dalam Tradisi Ngejot di Bali. Ta'dibuna: Jurnal Pendidikan Islam, $8(2)$.

Saihu. (2020). Pendidikan Sosial yang Terkandung dalam Surat At-Taubah Ayat 71-72. Edukasi Islami: Jurnal Pendidikan Islam, 09(01).

Sari, Renny Nirwana. Perilaku Remaja Zaman Now pada Siswa SMP X di Sidoarjo. Sains Psikologi, 8(1): 171176.

Sutikno. (2013). Pola Pendidikan Islam dalam Surat Luqman Ayat 12-19. Jurnal Pendidikan Agama Islam (JPAI) FTK UIN Sunan Ampel Surabaya, 1(2).: 292.

S, Wahyuni. (2012). Hubungan Antara Pengetahuan Remaja Tentang Penyakit Menular Seksual (PMS) dengan Jenis Kelamin dan Sumber Informasi di SMAN Banda Aceh. Jurnal Ilmiah Stikes U'budiyah, 1(2).

Yaqin, M.A. (2016). Pendidikan Agama Islam dan Penanggulangan Kenakalan Siswa (Studi Kasus Mts Hasanah Surabaya). Pendidikan Agama Islam, 4(2).: 294-314.

Yusriyah. (2017). Penanggulangan Kenakalan Remaja Melalui Pendidikan Islam. Jurnal Kependidikan, 5(1).: 57-60.

\section{Sumber dari Buku}

Arifiyani, N. (2015). Penanggulangan Kenakalan Remaja Menurut Konsep Kartini Kartono Ditinjau dari Perspektif Pendidikan Islam. Semarang: Universitas Negeri Walisongo.

Astuti, F. (2011). Pengaruh Bimbingan Konseling Agama Islam dalam Mengatasi Kenakalan Remaja di SMA 
Negeri 3 Kota Tangerang Selatan. Jakarta: UIN SYARIF HIDAYATULLAH JAKARTA.

Azra, A. (2012). Pendidikan Islam Tradisi dan Moderanisasi di Tengah Tantangan Milenium III. Jakarta: Kencana Prenada Media Grup.

BKKBN. (2001). Remaja Mengenai Dirinya. Jakarta.

Lisnawati. (2015). Hubungan Kenakalan Remaja dengan Pendidikan Akhlak di Dusun III RT 08 Kelurahan Ibul Besar Kecamatan Pemulutan Kabupaten Ogan Ilir. Palembang, Sumatera Selatan: Universitas Muhammadiyah Palembang.

Maunareng, F. (2017). Pengertian istilah "Zaman Now"." Kompasiana, 4 November 2017: www.kompasiana.com.

Mujib, Abdul \& Jusuf Mudzakkir. (2010). Ilmu Pendidikan Islam. Jakarta: Kencana

Setiawan, D. (2018). Darurat Pornografi pada anak SD, Orang Tua Harus Tingkatkan Pengawasan." KPAI, 31 Januari 2018: http://www.kpai.go.id/author/davit.

Setiawan, I. (2020). Komunitas Sukses 2010."

Komunitassukses2010.blogspot.com. April 2013. http://komunitassukses2010.blogspot.c om/2013/04/makalah-dampak-positifdan-negatif.html (diakses Januari 10, 2020).

Sumiati. (2009). Kesehatan Jiwa Remaja dan Konseling. Jakarta: TIM Jakarta. 